\title{
Uropathogens and their Susceptibility Patterns among Hospitalized Patients in a Tertiary Care Centre in Rajamahendravaram, India
}

\author{
P. Gowthami and A. Heraman Singh* \\ Department of Microbiology, GSL Medical College, Rajahmundry, A.P., India \\ *Corresponding author
}

\begin{tabular}{|l|}
\hline K e y w o r d s \\
UTIs, Gram negative \\
uropathogens, \\
Hospitalized patients, \\
Antimicrobial \\
susceptibility
\end{tabular}

A B S T R A C T
Urinary tract infections are one of the most common hospital-acquired infections, accounting to as many as $35 \%$ of nosocomial infections. In addition, UTIs are a leading cause of gram-negative sepsis in hospitalized patients. Early diagnosis and treatment of UTIs are essential in preventing urosepsis. This study is done to become familiar with the common uropathogens along with their antimicrobial susceptibility patterns among hospitalized patients in our setup. During the study period from June 2016 to September 2017, 520 urine samples collected from hospitalized patients were processed by microscopy and bacterial culture. Bacterial growth suggestive of significant bacteriuria (> $10^{5} \mathrm{CFU} / \mathrm{ml}$ ) was identified by standard biochemical tests and subjected to antimicrobial susceptibility test. Escherichia coli (42.2\%), Klebsiella sps (27.7\%) and Pseudomonas sps $(17.7 \%)$ were the common uropathogens isolated in this study. Others were Staphylococcus aureus, Acinetobacter sps, and Enterococcus sps. Gram negative uropathogens demonstrated highest sensitivity to imipenem, nitrofurantoin and piperacillin tazobactam combination and moderate sensitivity to gentamicin, amikacin and ciprofloxacin. Their sensitivity to commonly used antibiotics like cephalosporins, amoxiclavulanic acid was relatively poor. This study should guide our clinicians to plan effective empiric treatment regimens in the management of UTIs and control of urosepsis in hospitalized patients.

\section{Introduction}

Urinary tract infections are the most common hospital-acquired infections, accounting to as many as $35 \%$ of nosocomial infections. In addition, UTIs are a leading cause of gramnegative sepsis in hospitalized patients.

Early diagnosis and treatment of UTIs are essential in preventing urosepsis and reduce the rate of morbidity and mortality (Patricia, 2014). Studies clearly demonstrate increasing antibiotic resistance in uropathogens causing both community and nosocomially acquired UTIs (Gupta et al., 1999). Given the continuing evolution of drug resistance, there is a need for ongoing antimicrobial resistance surveillance to accurately monitor trends and recommend effective empiric treatment regimens (Walter E. Stamm and Ragnar Norrby, 2001). Given the situation, Knowledge of common uropathogens and their antimicrobial susceptibility patterns in local scenario is essential. 


\section{Objective of the study}

This study was done to become familiar with the common uropathogens along with their antimicrobial susceptibility patterns among hospitalized patients in our setup.

\section{Materials and Methods}

During the study period from June 2016 to September 2017, 520 urine samples collected from hospitalized patients were processed by microscopy and bacterial culture. Urine samples showing pus cells more than 10 per high power (40 times) field were given significance.

Semiquantitative urine culture using a calibrated loop was used to isolate bacterial pathogens. The urine samples were inoculated on nutrient agar, blood agar and MacConkey agar and incubated aerobically at $37^{\circ} \mathrm{c}$ for $24-$ 48 hours.

Pure bacterial growth suggestive of significant bacteriuria (> $10{ }^{5} \mathrm{CFU} / \mathrm{ml}$ ) was identified by standard biochemical tests and subjected to antimicrobial susceptibility test by using Kirby-Bauer disc diffusion method and the results were interpreted following CLSI guidelines (Gerald Colle et al., 2008; Clinical and Laboratory Standard Institute, 2012).

\section{Results and Discussion}

Out of 520 urine samples processed 180 demonstrated significant bacteriuria. UTIs were more common among females (42.33\%) than in males $(26.01 \%)$ as shown in Table 1. Gram negative bacilli (GNB) were the predominant pathogens $(90.55 \%)$ isolated in the present study among which Escherichia coli was the main pathogen $(42.2 \%)$ followed by Klebsiella species (27.7\%), Pseudomonas aeruginosa $(17.7 \%)$, Proteus sp $(2.77 \%)$, and Acinetobacter sp (0.55\%). Other Gram positive cocci (GPC) uropathogens isolated were Staphylococcus aureus (6.11\%), Coagulase negative Staphylococci (CONS) (2.22\%), and Enterococci sp $(0.55 \%)$ as shown in Table 2. The antimicrobial sensitivity patterns among isolated uropathogens were shown in Table 3 and 4.

UTI is considered as the most common hospital acquired infection constituting up to $35 \%$ of nosocomial infection and is regarded as a vital factor for the outbreak of bacteremia among hospitalized patients (Vasudevan, 2014). Long term hospitalized patients with indwelling urinary catheters and patients undergoing urological treatment are prone to UTIs (Vasudevan, 2014).

The pathogens accountable for the infection instigate from the individual's endogenous flora and the moist environment of the hospital aggravates the condition (Vasudevan, 2014). This study was done to become familiar with the common uropathogens along with their antimicrobial susceptibility patterns among hospitalized patients in our setup.

UTIs were more common among females $(42.33 \%)$ than in males $(26.01 \%)$, which could be attributed to their anatomy, the short and wide urethra in close proximity to anus (Vasudevan, 2014; Acharya et al., 2011; Mansour et al., 2009). The infection rate is low in males owing to the longer course of the urethra and bacteriostatic properties of prostate secretions (Tada Dharmishtha et al., 2012).

E. coli was the predominant pathogen (42.2\%) associated with UTI in our study. This high rate which correlates with many studies reported could be attributed to its commensal nature in the intestinal tract and consequent fecal contamination due to poor hygiene and moist hospitalized conditions (Vasudevan, 2014; Ezeigbo et al., 2016). 


\begin{tabular}{|c|l|c|}
\multicolumn{2}{|c|}{$\begin{array}{c}\text { Table.1 Frequency of bacterial pathogens isolated } \\
\text { from patients with UTI }\end{array}$} \\
\hline S. No & \multicolumn{1}{|c|}{ Pathogen } & $\begin{array}{c}\text { Number of } \\
\text { pathogens }(\mathbf{\%})\end{array}$ \\
\hline $\mathbf{1}$ & Escherichia coli & $76(42.2)$ \\
\hline $\mathbf{2}$ & Klebsiella sp & $50(27.7)$ \\
\hline $\mathbf{3}$ & Pseudomonas aeruginosa & $32(17.7)$ \\
\hline $\mathbf{4}$ & Staph aureus & $11(6.11)$ \\
\hline $\mathbf{5}$ & Proteus sp & $5(2.77)$ \\
\hline $\mathbf{6}$ & CONS & $4(2.22)$ \\
\hline 7 & Acinetobacter sp & $1(0.55)$ \\
\hline $\mathbf{8}$ & Enterobacter sp & $1(0.55)$ \\
\hline & Total & $\mathbf{1 8 0}$ \\
\hline
\end{tabular}

\begin{tabular}{|l|c|c|}
\hline \multicolumn{2}{|c|}{ Table.2 Gender wise distribution of UTI } \\
\hline Gender & Total cases & Positive cases \\
\hline Male & 246 & $64(26.01)$ \\
\hline Female & 274 & $116(42.33)$ \\
\hline Total & $\mathbf{5 2 0}$ & $\mathbf{1 8 0}(\mathbf{3 4 . 6 1})$ \\
\hline
\end{tabular}

\section{Table.3 Antimicrobial sensitivity patterns in \% among GNB isolates ( $\mathrm{n}=163$ )}

\begin{tabular}{|c|c|c|c|c|c|c|}
\hline S. No & $\begin{array}{c}\text { Name of the Drug } \\
\text { (Strength) }\end{array}$ & $\begin{array}{l}\text { E. coli } \\
(n=76)\end{array}$ & $\begin{array}{l}\text { Klebsiella } \\
\text { sp }(n=50)\end{array}$ & $\begin{array}{c}\text { Pseudomonas } \\
\text { aeruginosa }(n=32)\end{array}$ & $\begin{array}{l}\text { Proteus. } \\
\text { Sp }(n=5)\end{array}$ & $\begin{array}{l}\text { Range of } \\
\text { sensitivity }\end{array}$ \\
\hline 1 & Ampicillin (10) & 8 & 4 & NA & 0 & $0-8$ \\
\hline 2 & $\begin{array}{l}\text { Amoxicillin- } \\
\text { clavulanic acid (20/10) }\end{array}$ & 18.42 & 8 & NA & 0 & $0-18.42$ \\
\hline 3 & Cefoxitin (30) & 50 & 48 & NA & 0 & $0-50$ \\
\hline 4 & Cefotaxime (30) & 31.58 & 48 & NA & 40 & $31.58-48$ \\
\hline 5 & Ceftazidime (30) & 53.95 & 34 & 40.62 & 0 & $0-53.95$ \\
\hline 6 & Cotrimoxazole (25) & 36.84 & 50 & NA & 0 & $0-50$ \\
\hline 7 & Gentamicin (10) & 68.42 & 78 & 81.25 & 100 & $68.42-100$ \\
\hline 8 & Amikacin (30) & 69.74 & 78 & 100 & 100 & $69.74-100$ \\
\hline 9 & Ciprofloxacin (5) & 43.42 & 72 & 59.37 & 60 & $43.42-72$ \\
\hline 10 & $\begin{array}{l}\text { Piperacillin- } \\
\text { Tazobactam (100/10) }\end{array}$ & 85.52 & 88 & 59.37 & 100 & $59.37-100$ \\
\hline 11 & Imipenem (10) & 94.74 & 100 & 100 & 100 & $94.74-100$ \\
\hline 12 & Nitrofurantoin (300) & 96.05 & 80 & NA & 80 & $80-96.05$ \\
\hline 13 & Norfloxacin (10) & 39.47 & 54 & NA & 40 & $39.47-54$ \\
\hline 14 & Levofloxacin (5) & NA & NA & 59.37 & NA & NA \\
\hline 15 & Cefepime (30) & NA & NA & 40.62 & NA & NA \\
\hline 16 & Aztreonam (30) & NA & NA & 65.62 & NA & NA \\
\hline
\end{tabular}




\begin{tabular}{|c|c|c|}
\begin{tabular}{|} 
Table.4 Antimicrobial sensitivity pattern in \% among S. \\
aureus isolates $(\mathbf{n}=\mathbf{1 1})$
\end{tabular} \\
\hline S. No & Name of the antibiotic (Strength) & S. aureus \\
\hline $\mathbf{1}$ & Penicillin (10) & 0 \\
\hline $\mathbf{2}$ & Cefoxitin (30) & 63.63 \\
\hline $\mathbf{3}$ & Erythromycin (15) & 36.36 \\
\hline $\mathbf{4}$ & Clindamycin (2) & 45.45 \\
\hline $\mathbf{5}$ & Cotrimoxazole (25) & 45.45 \\
\hline $\mathbf{6}$ & Gentamicin (10) & 90.90 \\
\hline $\mathbf{7}$ & Ciprofloxacin (5) & 63.63 \\
\hline $\mathbf{8}$ & Vancomycin & 81.81 \\
\hline $\mathbf{9}$ & Teicoplanin (30) & 36.36 \\
\hline $\mathbf{1 0}$ & Doxycycline (30) & 36.36 \\
\hline $\mathbf{1 1}$ & Linezolid (30) & 81.81 \\
\hline $\mathbf{1 2}$ & Chloramphenicol (30) & 81.81 \\
\hline $\mathbf{1 3}$ & Nitrofurantoin (10) & 90.90 \\
\hline $\mathbf{1 4}$ & Norfloxacin (300) & 36.36 \\
\hline
\end{tabular}

The other common bacterial isolates were Klebsiella species (27.7\%) followed by Pseudomonas aeruginosa (17.7\%) which correlates with study by (Shirishkumar Patel et al., 2012). Length of hospital stay, urinary catheterization, immunosuppression and diabetes mellitus could be the risk factors for acquisition of these strains (Vasudevan, 2014).

However, in addition to the predominating GNB $(90.55 \%)$ isolated in our study, the significance of $S$. aureus colonizing the perinium in hospitalized patients cannot be denied as they all can exhibit antimicrobial resistance and enhance the rate of morbidity and mortality (Vasudevan, 2014).

In this study sensitivity exhibited by GNB to tested beta lactam group of antibiotics like ampicillin, amoxyclav, cefoxitin, cefotaxime, ceftazidime, is low $(0 \%-53.95 \%)$. The resistance to these commonly used drugs may be due to increased prevalence in betalactamase with or without ESBL in hospital environmental bacteria (Tada Dharmishtha et al., 2012).
Among the other beta lactams, good levels of sensitivity has been demonstrated to less commonly used antibiotics like piperacillin/tazobactam $(59.37 \%-100 \%)$ and imipenem $(94.74 \%-100 \%)$.

Both aminoglycosides used in the study were found to be good sensitive drugs against GNB isolated with sensitivity levels in the range of $68.42 \%-100 \%$. Quinolones like ciprofloxacin, levofloxacin, norfloxacin demonstrated moderate sensitivity in the range of $39.47 \%-72 \%$.

Among the other oral antimicrobials cotrimoxazole demonstrated low sensitivity $(0 \%-50 \%)$ but nitrofurantoin retained good activity with a sensitivity range of $80 \%$ $96.05 \%$.

S. aureus demonstrated good sensitivity to antibiotics like nitrofurantoin, chloramphenicol, linezolid, gentamicin and vancomycin in the range of $81.81 \%-90.90 \%$ followed by ciprofloxacin and cefoxitin with a moderate sensitivity of $63.63 \%$. The sensitivity was low to penicillin, 
erythromycin, clindamycin, cotrimoxazole, doxycycline, teicoplanin and norfloxacin with a range of $0 \%-45.45 \%$.

Overall, Nitrofurantoin demonstrated good activity against most uropathogens including both GNB and GPC which correlates well with a study from L Shakti. It acts at multiple targets in the bacterial cell. Resistance usually develops through stepwise mutations and the resistant mutants growth rate is low and their selection is prohibited at the therapeutic urinary concentrations of the drug. This may explain the lack of resistance to this drug even after 60 years of use. As it is usually well tolerated and also has good safety profile for use in pregnancy, it may be recommended on empirical basis in treating UTIs at least in uncomplicated cases (Shakti and Veeraraghavan, 2015).

However, complicated UTIs are associated with more tissue invasion and can develop urosepsis rapidly. In these cases, Piperacillintazobactam with or without gentamicin to which GNB isolated demonstrated good sensitivity may be considered on empirical basis. In penicillin allergy cases quinolones with gentamicin may be considered. Imipenem may be reserved for highly resistant ESBL cases and may be considered after culture sensitivity report.

\section{Acknowledgements}

This paper is presented in the Indian Association of Medical Microbiology, TAPS chapter 2018, on 19 to 21 January 2018.

\section{References}

Acharya, A., R Gautam, L Subedee. Uropathogens and their susceptibility pattern in Bharatpur, Nepal. Nepal Med Coll J 2011; 13(1): 30 - 33.
Clinical and Laboratory Standard Institute, 2012. Performance standards for antimicrobial susceptibility testing. Clinical and Laboratory Standards Institute, Wayne. $22^{\text {nd }}$ Informational Supplement, 32 (33).

Ezeigbo, R., R.I.A. Nnadozie, $\mathrm{N}$ Asuoha Chuks, et al., Incidence of urinary tract infection (UTI) among pregnant women attending antenatal clinics at some selected hospitals in Aba, Southeastern Nigeria. International Journal of Current Microbiology and Applied Sciences 2016; 5 (1): 193 - 199.

Gerald Colle, J., Andrew G. Fraser, Barrie P. Marmion, Anthony Simmons. Mackie \& McCartney practical medical microbiology. $14^{\text {th }}$ edition, Churchill Livingstone, Elsevier, 2008.

Gupta K, Scholes D, Stamm WE. Increasing prevalence of antimicrobial resistance among uropathogens causing acute uncomplicated cystitis in women. JAMA 1999; 281: $736-8$.

Mansour A, Manijeh M, Zohreh P. Study of bacteria isolated from urinary tract infections and determination of their susceptibility to antibiotics. Jundishapur Journal of Microbiology 2009; 2(3): $118-123$.

Patricia M. Tille. Infections of the urinary tract. Bailey \& Scott's Diagnostic microbiology. $13^{\text {th }}$ edition, Elsevier mosby, 2014; 919 - 30 .

Shakti L, and Veeraraghavan B. Advantage and limitations of nitrofurantoin in multidrug resistant Indian scenario. Indian Journal of medical microbiology 2015; 33 (4): 477 - 481.

Shirishkumar Patel, Pankaj kumar P Taviad, Mala Sinha, et al., Urinary tract infections (UTI) among patients at G.G hospital \& medical college, Jamnagar. National journal of community medicine 2012; 3 (2): 138 -141. 
Tada Dharmishtha G, Gandhi Paragi J, Patel Kiran N. A study on antibiotic related resistance in UTI patients: A comparison between community acquired and hospital acquired E. coli. National journal of community medicine 2012; 3 (2): 255 -258.

Vasudevan R. Urinary tract infection: An overview of the infection and the associated risk factors. J Microbiol Exp 2014; 1 (2): $00008 . \quad$ DOI: 10.15406/jmen.2014.01.00008.

Walter E. Stamm and S. Ragnar Norrby. Urinary tract infections: Disease panorama and challenges. The Journal of infectious diseases 2001; 183 (Suppl 1): $S 1-4$.

\section{How to cite this article:}

Gowthami, P. and Heraman Singh, A. 2018. Uropathogens and their Susceptibility Patterns among Hospitalized Patients in a Tertiary Care Centre in Rajamahendravaram, India. Int.J.Curr.Microbiol.App.Sci. 7(06): 1026-1031. doi: https://doi.org/10.20546/ijcmas.2018.706.121 